\title{
Myeloma at Cross Roads in India
}

\author{
Uday Yanamandra ${ }^{1} \cdot$ Pankaj Malhotra ${ }^{2}$
}

Published online: 8 October 2018

(C) Indian Society of Hematology and Blood Transfusion 2018

The global burden of myeloma is highly variable among countries with increase in incidence uniformly and substantially since 1990 . The age standardized incidence rates (ASIR) of myeloma globally is 2.1 per million (95\% CI: 1.8-2.24) [1]. The countries with high sociodemographic incidence (SDI) have higher ASIR, whereas countries with low SDI have lower ASIR. The largest increase in incidence in recent years are seen in middle and low-middle SDI countries. East Asia (China, Taiwan, and North Korea) has recorded a $262 \%$ rise in the myeloma incidence from 1990 to 2016 [1]. India is depicted along with countries with least ASIR, despite low SDI [1]. This poor representation could be attributed to lack of epidemiological studies and non-availability of myeloma registry to systematically record the incidence rates in our country. To identify factual myeloma related information, Indian myeloma academic groupe (IMAGe, http://imagesociety.co.in) has launched a nation-wide myeloma registry (care4myeloma.in).

Myeloma occurs a decade earlier in our country than the western population [2]. This has a great impact on the disease/state economics in a low socioeconomic state like ours, as it affects economically productive age. Either

Pankaj Malhotra

malhotrapankaj@hotmail.com;

http://pgimer.edu.in

Uday Yanamandra

udayj2@gmail.com

1 Department of Haematology and Stem Cell Transplant, Army Hospital (Research and Referral), New Delhi, India

2 Department of Internal Medicine, Postgraduate Institute of Medical Education and Research (PGIMER), Chandigarh 160012, India mortality or prolonged survival can have financial impacts by cessation of financial support to the family in the first scenario and continuous financial burden for this remitting relapsing disease. This is in addition to the cost incurred for disease associated morbidity in the second scenario. Also, resource constraints take a heavy toll on the overall outcomes of the disease [3]. The average cost of therapy per patient in India with and without autologous stem cell transplant (ASCT) from a societal perspective is INR 395,527 (USD 6085) and INR 62,785 (USD 966) respectively [4]. As per the world bone marrow transplant (WBMT) registry we stand last in ASCT rate at 1-137/ 10 million population [5]. In the last 5 years, the access to ASCT has increased with rising number of transplant centers and cost per transplant showing a declining trend $[4,6]$.

Access to effective therapy is very limited, particularly in low SDI countries like India despite amongst the best for drug availability globally [1]. The therapeutic armamentarium of myeloma has increased in the recent years with the availability of the five newer drugs in the Indian market. Increasing number of patients are prescribed these newer agents with a concurrent increase in the costs. Generics and biosimilars, a bastion of the Indian pharma industry, is narrowing this gap of drug availability and access. According to the law of pharmaco-economics increase in demand shall bring down the cost of the supplies, both by decreasing the production costs (when in bulk) and by increasing market competition by rise in competitors.

Myeloma diagnostics have shown a tremendous improvement in the country with increasing number of patients being diagnosed in time. The access and role of flow cytometry, immunological assays, and cytogenetics in myeloma are increasing [7]. Owing to the extensive nationwide networks of private laboratories, the 
diagnostics including complicated high-end tests are possible from any part of the country. Considering the poor cost benefit ratio and expertise required for the in-house testing, the majority of the diagnostic workup is still outsourced in India. The major flipside of this outsourced evaluation is lack of insight into the reporting quality, preanalytical confounders from sampling to testing, and the dwindling confidence in the expertise with no cross checks in place unlike for in-house testing. What we still lack is nationwide standardization (particularly for plasma enriched cytogenetics and flowcytometry) for homogenous results and better quality of reporting.

Despite the improvements in the varied aspects of the myeloma management, the major challenge we face is the heterogeneity of care provided by the physicians in India $[8,9]$. We require nation specific consensus guidelines which take into consideration the local issues, heterogeneity of the resources and biology of the Indian patients. The IMAGe is working in this direction by bringing together all myeloma experts and preparing India specific guidelines [10].

Another fatal flaw of myeloma care in a multilinguistic country like ours with poor literacy rates and poor socioeconomic status is the poor patient compliance/understanding of the disease [11]. This has been a major foray of IMAGe with a dedicated mobile application (care4myeloma mobile app) and patient information brochures freely available in different languages on the society website (https://imagesociety.co.in/for-patients/patientinformation-brochure/).

We in India are truly at the cross roads of myeloma care with changing trends from a patient-based approach to a society-based approach. We hope to bring larger changes to overall outcomes and outreach patients at every corner of the country with this newer approach.

Financial Support This research received no specific grant from any funding agency, commercial or not-for-profit sectors.

\section{Compliance with Etical Standards}

Conflict of interest The authors declare that they have no conflict of interest.

\section{References}

1. Cowan AJ, Allen C, Barac A, Basaleem H, Bensenor I, Curado MP et al (2018) Global burden of multiple myeloma: a systematic analysis for the global burden of disease study 2016. JAMA Oncol 4(9):7-1221

2. Yanamandra U, Saini N, Chauhan P, Sharma T, Khadwal A, Prakash G et al (2018) AYA-myeloma: real-world, single-center experience over last 5 years. J Adolesc Young Adult Oncol 7(1):4-120

3. Tan D, Lee JH, Chen W, Shimizu K, Hou J, Suzuki K, et al. (2018) Recent advances in the management of multiple myeloma: clinical impact based on resource-stratification. In: Consensus statement of the Asian myeloma network at the 16th international myeloma workshop. Leukemia and lymphoma. pp 1-13

4. Prinja S, Kaur G, Malhotra P, Jyani G, Ramachandran R, Bahuguna $\mathrm{P}$ et al (2017) Cost-effectiveness of autologous stem cell treatment as compared to conventional chemotherapy for treatment of multiple myeloma in India. Indian J Hematol Blood Transfus Off J Indian Soc Hematol Blood Transfus 33(1):31-40

5. Gratwohl A, Pasquini MC, Aljurf M, Atsuta Y, Baldomero H, Foeken L et al (2015) One million haemopoietic stem-cell transplants: a retrospective observational study. Lancet Haematol 2(3):e91-100

6. Malhotra P, Yanamandra U, Khadwal A, Prakash G, Lad D, Law AD et al (2018) Autologous stem cell transplantation for multiple myeloma: single centre experience from North India. Indian $\mathbf{J}$ Hematol Blood Transfus Off $\mathbf{J}$ Indian Soc Hematol Blood Transfus 34(2):7-261

7. Mallik N, Nampoothiri RV, Sreedharanunni S, Singh Sachdeva MU, Malhotra P, Varma N (2018) Multiple myeloma or lymphoma? The increasing role of flow cytometry and serum-free light chain assay. Indian J Pathol Microbiol 61(1):50-149

8. Jain A, Malhotra P (2018) Plasma cell dyscrasias in India-2017 updates. Indian $\mathrm{J}$ Hematol Blood Transfus Off $\mathrm{J}$ Indian Soc Hematol Blood Transfus 34(1):1-4

9. Kumar L, Verma R, Radhakrishnan VR (2010) Recent advances in the management of multiple myeloma. Natl Med $\mathrm{J}$ India 23(4):8-210

10. Yanamandra U, Khattry N, Kumar S, Raje N, Jain A, Jagannath S et al (2017) Consensus in the management of multiple myeloma in India at myeloma state of the art 2016 conference. Indian J Hematol Blood Transfus Off $\mathbf{J}$ Indian Soc Hematol Blood Transfus 33(1):15-21

11. Huang XJ, Liu K, Ritchie D, Andersson B, Lu J, Hou J et al (2017) Hematology oncology practice in the Asia-Pacific APHCON survey results from the 6th international hematologic malignancies conference: bridging the gap 2015, Beijing, China. Oncotarget 8(25):30-41620 